Resolution No. 1

IAU Symposium No. 82 expresses its satisfaction with the methods employed by the International Latitude Observatory of Mizusawa in compiling and re-reducing the past International Latitude Service data.

The symposium further expresses its gratitude to the staff of the International Latitude Observatory of Mizusawa in recognition of the magnitude of the task.

Resolution No. 2

IAU Symposium No. 82 recommends that the presidents of Commissions 19 and 31 appoint a working group to promote a comparative evaluation of the techniques for the determination of the rotation of the Earth and to make recommendations for a new international programme for observation and analysis in order to provide high-quality data for practical applications and fundamental geophysical studies.

\title{
WORKING GROUP MEMBERSHIP
}

Chairman: G. A. Wilkins (UK)

Lunar Laser: E. C. Silverberg (USA)

Y. Kozai (Japan)

Yu. L. Kokurin (USSR)

Satellite Laser: D. E. Smith (USA)

G. Veis (Greece)

L. Aardoom (Holland)

Doppler: R. J. Anderle (USA)

F. Nouel (France)

Radio Interferometry: W. C. Melbourne (USA)

W. E. Carter (USA)

B. Elsmore (UK)

Classical Methods: Y. S. Yatskiv (USSR)

R. O. Vicente (Portugal)

BIH Representative: M. Feissel (France)

IPMS Representative: K. Yokoyama (Japan) 